\title{
Rice Bran Phenolic Compounds Regulate Genes Associated with Antioxidant and Anti-Inflammatory Activity in Human Umbilical Vein Endothelial Cells with Induced Oxidative Stress
}

\author{
Nancy Saji ${ }^{1,2}$, Nidhish Francis ${ }^{1,3}$, Christopher L. Blanchard ${ }^{1,2}$, Lachlan J. Schwarz ${ }^{1,4}$ and \\ Abishek B. Santhakumar 1,2,*(D) \\ 1 Australian Research Council (ARC) Industrial Transformation Training Centre (ITTC) for Functional Grains, \\ Graham Centre for Agricultural Innovation, Charles Sturt University, Wagga Wagga, \\ New South Wales 2650, Australia; nsaji@csu.edu.au (N.S.); nfrancis@csu.edu.au (N.F.); \\ CBlanchard@csu.edu.au (C.L.B.); lschwarz@csu.edu.au (L.J.S.) \\ 2 School of Biomedical Sciences, Charles Sturt University, Locked Bag 588, Wagga Wagga, \\ New South Wales 2678, Australia \\ 3 School of Animal and Veterinary Sciences, Charles Sturt University, Locked Bag 588, Wagga Wagga, \\ New South Wales 2678, Australia \\ 4 School of Agricultural and Wine Sciences, Charles Sturt University, Locked Bag 588, Wagga Wagga, \\ New South Wales 2678, Australia \\ * Correspondence: asanthakumar@csu.edu.au
}

Received: 28 August 2019; Accepted: 20 September 2019; Published: 23 September 2019

\begin{abstract}
Oxidative stress, inflammation and endothelial dysfunction are associated with the development of cardiovascular and metabolic diseases. Phenolic extracts derived from rice bran (RB) are recognised to have antioxidant and anti-inflammatory potential. However, the underlying mechanisms remain unknown. Therefore, this study aimed to evaluate the ability of RB-derived phenolic extracts to modulate genes associated with antioxidant and anti-inflammatory pathways in human umbilical vein endothelial cells (HUVECs) under induced oxidative stress conditions. HUVECs under oxidative stress were treated with varying concentrations of RB phenolic extracts $(25-250 \mu \mathrm{g} / \mathrm{mL})$. Using quantitative real-time polymerase chain reaction, the expression of candidate genes that regulate antioxidant and anti-inflammatory pathways were determined. This included nuclear factor erythroid 2-related factor 2 (Nrf2), nicotinamide adenine dinucleotide phosphate: quinone oxidoreductase 1 (NQO1), heme oxygenase 1 (HO1), nicotinamide adenine dinucleotide phosphate oxidase 4 (NOX4), intercellular adhesion molecule 1 (ICAM1), endothelial nitric oxide synthase (eNOS), ectonucleoside triphosphate diphosphohydrolase 1 (CD39) and ecto-5' -nucleotidase (CD73). Phenolic extracts derived from RB down-regulated the expression of four genes, ICAM1, CD39, CD73 and NOX4 and up-regulated the expression of another four genes, Nrf2, NQO1, HO1 and eNOS, indicating an antioxidant/ anti-inflammatory effect for RB against endothelial dysfunction.
\end{abstract}

Keywords: rice bran; polyphenols; gene expression; endothelial function

\section{Introduction}

Endothelial dysfunction has been identified as a primary contributor to the progression of vascular disorders such as cardiovascular disease (CVD) and stroke [1]. The endothelium maintains vascular haemostasis and exerts anti-coagulant, anti-platelet and fibrinolytic properties [1]. However, oxidative stress resulting from an imbalance between pro-oxidants and antioxidants leads to an increase in the production of reactive oxygen species (ROS) in vascular tissue, consequently leading to the 
pathogenesis of CVD [2]. Several genes including nuclear factor erythroid 2-related factor 2 ( $N r f 2)$, nicotinamide adenine dinucleotide phosphate: quinone oxidoreductase 1 (NQO1), heme oxygenase 1 (HO1), nicotinamide adenine dinucleotide phosphate oxidase 4 (NOX4), intercellular adhesion molecule 1 (ICAM1), endothelial nitric oxide synthase (eNOS), ectonucleoside triphosphate diphosphohydrolase 1 (CD39) and ecto-5'-nucleotidase (CD73) regulate the production of ROS within the vasculature.

$N r f 2$ is a member of the basic leucine zipper transcription factor family that controls the expression of several genes, including NQO1 and HO1 [2]. NQO1, a cytosolic flavoenzyme, is expressed in tissues including epithelial, vascular endothelial and adipocytes [3], and HO1 is an enzyme involved in heme catabolism resulting in biliverdin, carbon monoxide and ferrous iron production [4]. Reduced expression and activity of cellular Nrf2, NQO1 or HO1 results in a failure of antioxidant and cytoprotective enzymes to regulate appropriately under oxidative stress conditions and is therefore associated with increased risk of CVD [3,4]. eNOS, primarily found in vascular endothelial cells, is involved in regulating vascular tone and blood clotting by generating protective nitric oxide (NO) molecules in the vasculature [5], thereby preventing the increased ROS production in endothelial cells.

NOX4, present in pulmonary arteries as a result of oxidative stress, can result in direct injury to cells, modulate various signalling cascades and regulate transcription factors [6]. NOX4 is thought to play a role in the regulation of cell growth or cell survival in endothelial cells, suggesting that NOX4 may play an essential role in the formation of atherosclerosis [6]. Furthermore, soluble cell adhesion molecules such as ICAM1 have been demonstrated to be responsible for the adhesion of circulating leucocytes to sites of inflammation and their accumulation in arterial walls, subsequently leading to progression of atherosclerosis [7]. During inflammation, purinergic mediators such as adenosine triphosphate (ATP) and adenosine diphosphate (ADP) initiate a series of pro-inflammatory responses [8]. Immunoregulatory enzymes such as $C D 39$ and $C D 73$ play a key role in regulating the duration, magnitude and chemical nature of purinergic signals delivered to cells, resulting in adenosine production [8]. The subsequent cascade of events ultimately shifts the pro-thrombotic ATP/ADP-rich environment to an anti-thrombotic, adenosine-rich environment [8].

Research into functional foods has considerably increased over the last decade. Consumption of functional foods to reduce the incidence of chronic health disorders has progressively resonated with health-conscious consumers. Several studies, both in vitro and in vivo, have provided evidence for the protective role of phytochemical compounds as part of a healthy diet, resulting in heart and vasculature protection against oxidative stress $[9,10]$. In particular, phenolic compounds derived from cereals, fruits and beverages are recognised to have anti-thrombotic activity and improve endothelial function [1]. A recent study conducted by our group has reported that whole grain coloured rice polyphenols may potentially target oxidative stress and inflammatory pathways associated with endothelial dysfunction [7].

Rice bran (RB), a by-product of the rice milling process, is recognised to contain a wide range of bioactive chemicals including a combination of polyphenols, $\gamma$-oryzanol and tocopherols, which are responsible for most of the antioxidant capacity observed [11]. However, the underlying signalling pathways that contribute to the potential antioxidant and anti-inflammatory properties of RB remains unclear. Therefore, this study aimed to determine the effect of RB phenolic extracts on regulating the expression of antioxidant (Nrf2, NQO1, HO1 and NOX4) and anti-inflammatory genes (ICAM1, eNOS, CD39 and CD73) in human umbilical vein endothelial cells (HUVECs) under simulated oxidative stress conditions.

\section{Results}

\subsection{Cytotoxicity of RB Phenolic Extracts on HUVECS}

The cell viability of HUVECs post $2 \mathrm{~h}$ exposure (Figure 1) to different concentrations of RB phenolic extracts has determined the optimal, non-toxic concentrations to be in the range of $25-250 \mu \mathrm{g} / \mathrm{mL}$. 


\section{Cytotoxicity assessment -2 h}

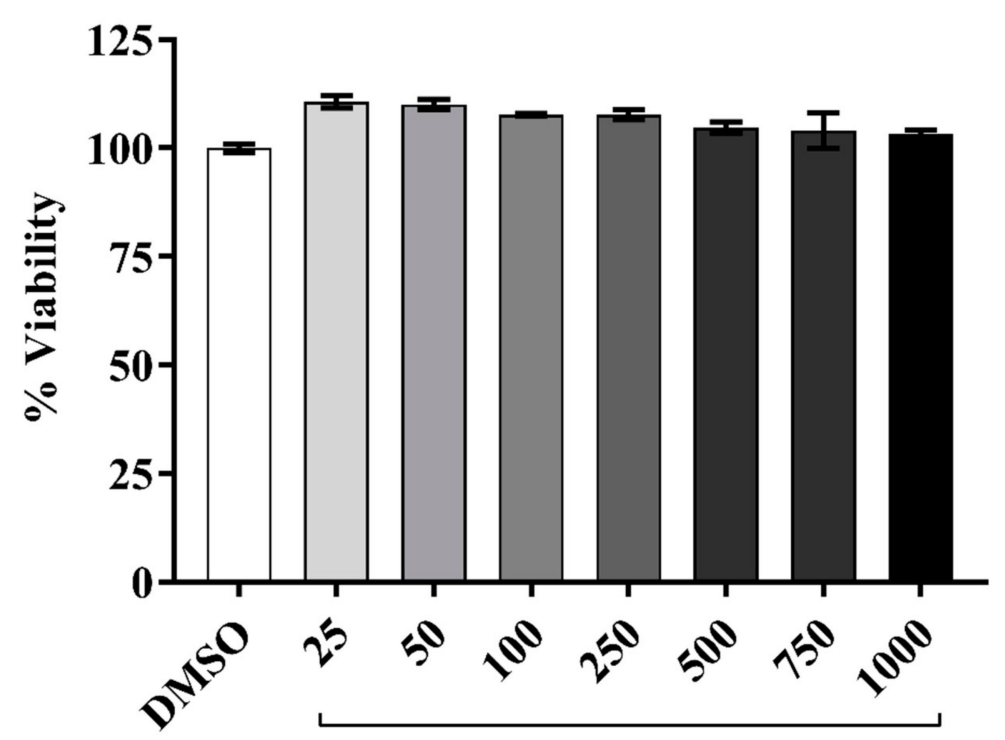

\section{RB extract concentrations $(\mu \mathrm{g} / \mathrm{mL})$}

Figure 1. Cytotoxicity results in HUVECs after $2 \mathrm{~h}$ post-exposure to different concentrations of RB phenolic extracts. The RB phenolic extracts did not display any cytotoxic effect on the HUVEC cells at any of the concentrations tested $(25-1000 \mu \mathrm{g} / \mathrm{mL})(n=3)$. Data is presented as mean \pm SEM. Dimethyl sulfoxide, DMSO; human umbilical vein endothelial cells, HUVEC; rice bran, RB.

\subsection{Effect of RB Phenolic Extracts on Antioxidant Genes under Oxidative Stress Conditions}

The influence of RB phenolic extracts on antioxidant genes in HUVECs (Figure 2) under oxidative stress conditions displayed a significant increase $(p<0.05)$ in the expression of Nrf2 and NQO1 genes was observed with pre-treatment at 100 and $250 \mu \mathrm{g} / \mathrm{mL}$ of RB phenolic extracts when compared to the $\mathrm{H}_{2} \mathrm{O}_{2}$ only treated group. The expression of $\mathrm{HO} 1$ gene was significantly increased when pre-treated with $250 \mu \mathrm{g} / \mathrm{mL}$ of RB phenolic extracts. In the NOX4 gene, a significant reduction in expression $(p<$ 0.001 ) was observed at the highest RB phenolic concentration of $250 \mu \mathrm{g} / \mathrm{mL}$. 
a)

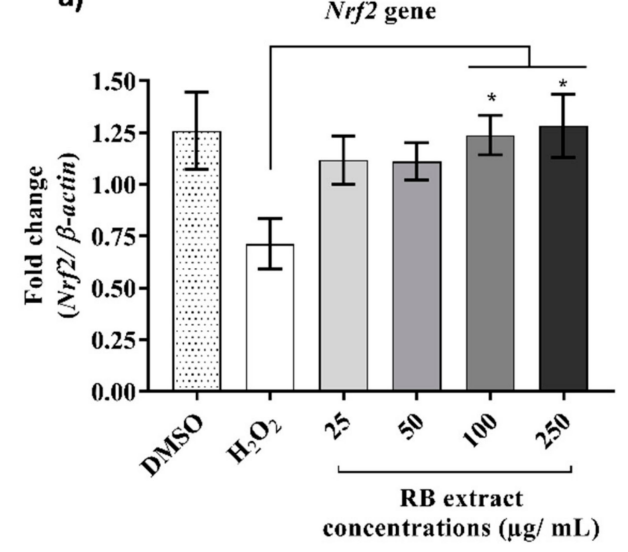

c)

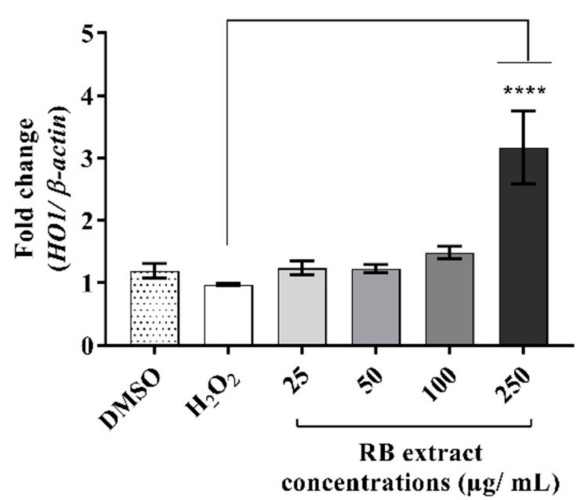

b)

NQOI gene

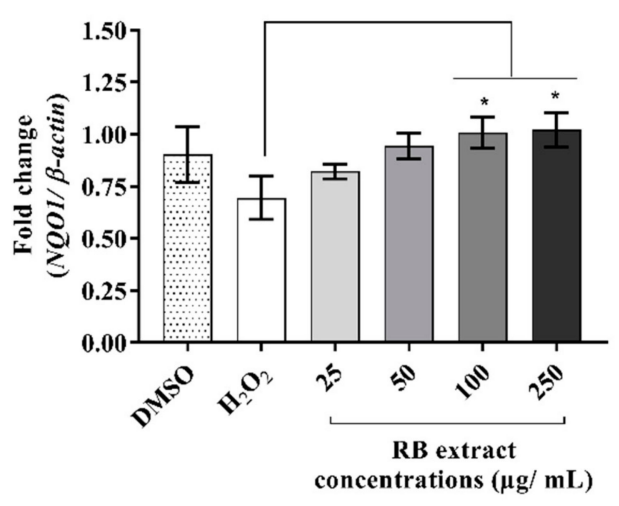

d)

NOX4 gene

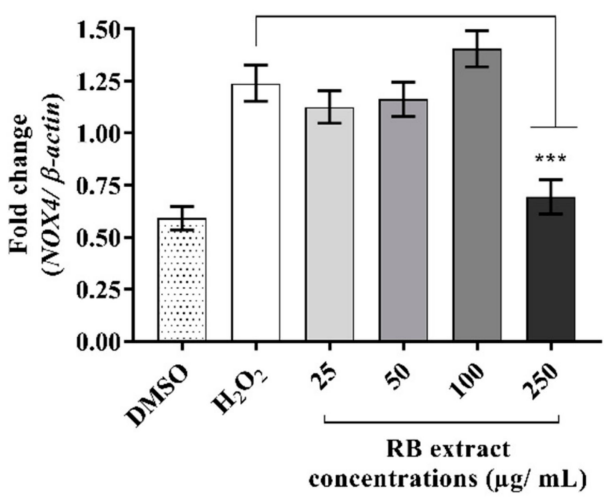

Figure 2. Effect of RB phenolic extracts on antioxidant genes. (a) Nrf2 (b) NQO1 (c) HO1 (d) NOX4 in HUVECs under oxidative stress conditions. A significant increase $(p<0.05)$ in the expression of $N r f 2$ and NQO1 genes was observed with pre-treatment at 100 and $250 \mu \mathrm{g} / \mathrm{mL}$ of RB phenolic extracts when compared to the $\mathrm{H}_{2} \mathrm{O}_{2}$ only treated group. The expression of $\mathrm{HO} 1$ gene was significantly increased when pre-treated with $250 \mu \mathrm{g} / \mathrm{mL}$ of RB phenolic extracts. In the NOX4 gene, a significant reduction in expression $(p<0.001)$ was observed at the highest RB phenolic concentration of $250 \mu \mathrm{g} / \mathrm{mL}$. The level of significance is indicated by the asterisks, whereby ${ }^{*} p<0.05,{ }^{* * *} p<0.001,{ }^{* * * *} p<0.0001 . n=3$. Data is presented as mean \pm SEM. Dimethyl sulfoxide, DMSO; hydrogen peroxide, $\mathrm{H}_{2} \mathrm{O}_{2}$; human umbilical vein endothelial cells, HUVEC; rice bran, RB; nuclear factor erythroid 2-related factor 2 (Nrf2); NADPH: quinone oxidoreductase 1 (NQO1); heme oxygenase 1 (HO1); NADPH oxidase 4 (NOX4).

\subsection{Effect of RB Phenolic Extracts on Anti-Inflammatory Genes under Oxidative Stress Conditions}

The influence of RB phenolic extracts on anti-inflammatory genes, ICAM1, eNOS, CD39 and CD73 in HUVECs (Figure 3) under oxidative stress conditions displayed a significant reduction $(p<0.0001)$ in the expression of ICAM1 and CD73 across all RB phenolic treatments $(25-250 \mu \mathrm{g} / \mathrm{mL})$. The expression of eNOS gene was significantly increased when pre-treated with $250 \mu \mathrm{g} / \mathrm{mL}$ of RB phenolic extracts. In CD39 gene, a significant reduction $(p<0.01)$ was observed at $250 \mu \mathrm{g} / \mathrm{mL}$ RB concentration. 
a)

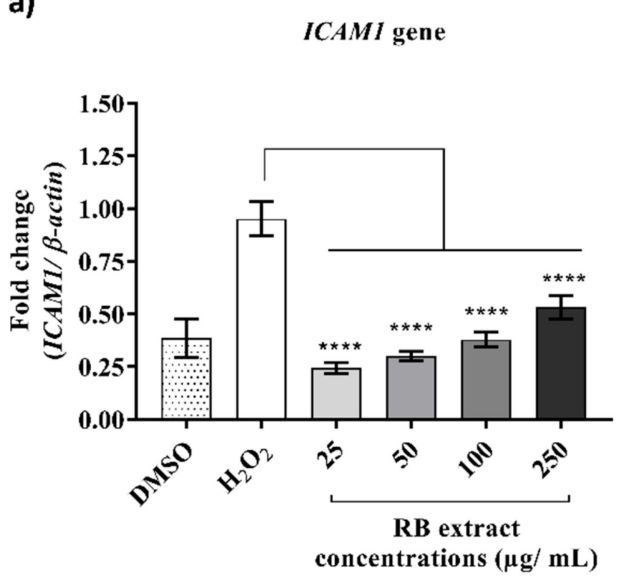

c)

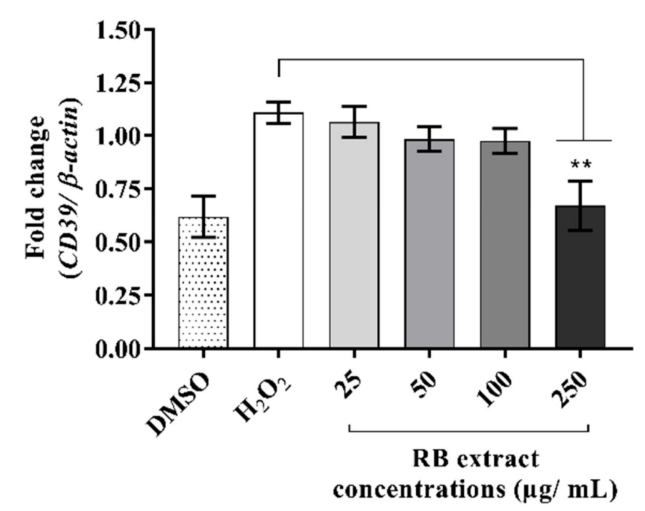

b)

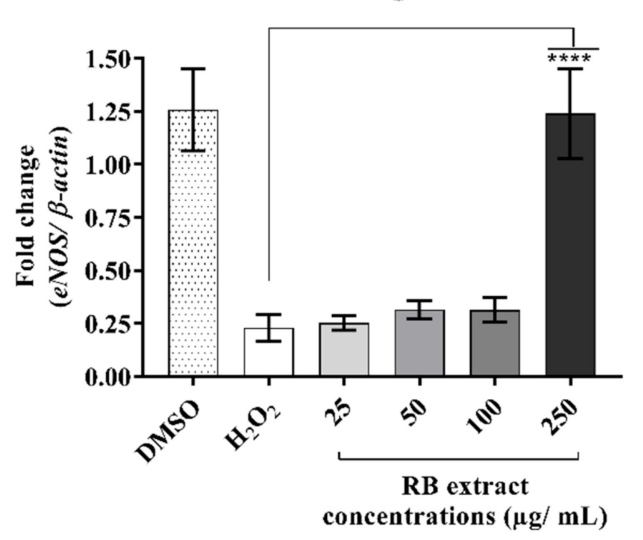

d)

CD73 gene

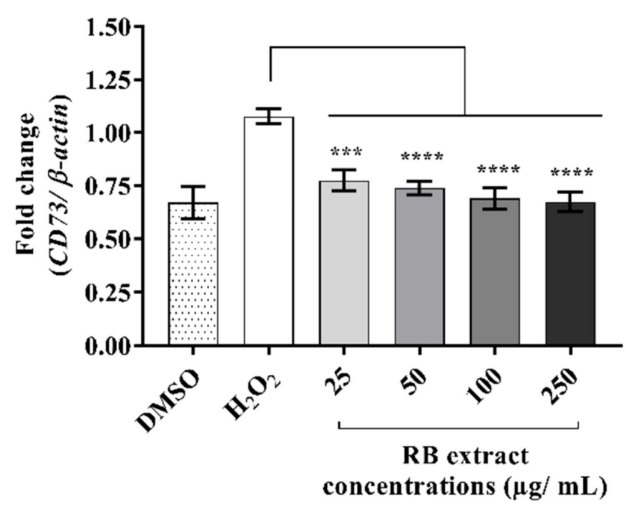

Figure 3. Effect of RB phenolic extracts on anti-inflammatory genes. (a) ICAM1 (b) eNOS (c) CD39 (d) $C D 73$ in HUVECs under oxidative stress conditions. A significant reduction $(p<0.0001)$ in the expression of ICAM1 and CD73 was seen across all RB phenolic treatments $(25-250 \mu \mathrm{g} / \mathrm{mL})$. The expression of eNOS gene was significantly increased when pre-treated with $250 \mu \mathrm{g} / \mathrm{mL}$ of RB phenolic extracts. In CD39 gene, a significant reduction $(p<0.01)$ was observed at $250 \mu \mathrm{g} / \mathrm{mL} \mathrm{RB}$ concentration. The level of significance is indicated by the asterisks, whereby ${ }^{* *} p<0.01,{ }^{* * *} p<0.001,{ }^{* * * *} p<0.0001 . n=3$. Data is presented as mean \pm SEM. Dimethyl sulfoxide, DMSO; hydrogen peroxide, $\mathrm{H}_{2} \mathrm{O}_{2}$; human umbilical vein endothelial cells, HUVEC; rice bran, RB; intercellular adhesion molecule 1 (ICAM1); endothelial nitric oxide synthase (eNOS); ectonucleoside triphosphate diphosphohydrolase 1 (CD39); ecto-5'-nucleotidase (CD73).

\section{Discussion}

Endothelial dysfunction is a hallmark of CVD, characterised by high levels of ROS, leading to oxidative stress and inflammation in the vasculature [2]. There are several reports on phenolic compounds that demonstrate protection against cardio-metabolic risk factors such as dyslipidemia, hypertension and glucose metabolism [7,12,13]. However, to the best of the authors' knowledge, there are no such reports on the cytoprotective effect of RB-phenolic compounds on endothelial function. As such, the present study is, to the best of the authors' knowledge, the first to detail the effects of RB-phenolic compounds on $\mathrm{H}_{2} \mathrm{O}_{2}$ induced endothelial dysfunction in HUVECs and provides evidence of the potential for RB phenolic compounds to regulate antioxidant and anti-inflammatory signalling pathways. 
RB was found to contain several bioactive chemicals including ferulic acid, $p$-coumaric acid, caffeic acid, vanillic acid, syringic acid, sinapic acid, feruloyl glycoside, shikimic acid, ethyl vanillate, tricin and their isomers with significant antioxidant activity (unpublished data). Previous examinations of phenolic bioavailability have identified that in particular, ferulic acid, one of the most abundant phenolics present in $\mathrm{RB}$, takes $2 \mathrm{~h}$ to reach maximal plasma concentration [14]. The cell viability of HUVECs post $2 \mathrm{~h} \mathrm{H}_{2} \mathrm{O}_{2}$ exposure (Figure 1) revealed the optimal, non-toxic concentrations of RB extracts to be in the range of $25-250 \mu \mathrm{g} / \mathrm{mL}$, as such, these concentrations were employed throughout the study.

\subsection{Effect on Antioxidant Genes under Oxidative Stress Conditions}

Results from this study have demonstrated the antioxidant potential of RB-derived phenolic compounds via up-regulation of Nrf2, NQO1, and HO1 expression and down-regulation of NOX4 expression (Figure 2). Nrf2 is a transcription factor known to play a significant role in regulating several antioxidant and cytoprotective genes via activation of promoters containing the antioxidant response element [4]. Normally, activation of Nrf2 up-regulates the production of detoxifying enzymes such as NQO1 and HO1 [9]. HO1 enzyme is usually involved in heme catabolism and is recognised to exert antioxidant affects by nullifying intracellular ROS. NQO1 enzyme exerts cardioprotective action against oxidative damage by preventing free radical formation from quinone derivatives by transforming the quinone to the redox stable hydroquinone [10]. Therefore, the modulation of $N r f 2$ and its downstream antioxidant signalling molecules such as NQO1 and HO1 may form the basis for a therapeutic strategy for various chronic diseases. Exposure to cytotoxic ROS has been shown to result in apoptosis of endothelial cells accompanied by reduced transcriptional activity of Nrf2 [15]. This study demonstrated that phenolic compounds derived from RB have a concentration-dependent increase on Nrf2, NQO1 and $\mathrm{HO} 1$ expression in $\mathrm{H}_{2} \mathrm{O}_{2}$ induced HUVECs (Figure 2). This finding is consistent with literature that demonstrated the effect of other plant polyphenols in modulating Nrf2 and associated enzyme expression. Patel and Maru [16] confirmed that polyphenols derived from black tea induced Nrf2 mediated antioxidant responsive element binding in mouse liver and lungs. Additionally, Ungvari et al. [9] have shown that resveratrol provided endothelial protection both in vitro and in vivo by the activation of Nrf2.

NOX isoforms are expressed in several vascular tissues and particularly in HUVECs. The expression level of NOX4 is recognised to be 100-fold higher than other isoforms, suggesting that NOX4 is the major source of ROS in the endothelial vasculature [17]. Within resting cells, NOX isoforms remain dormant; however, under stimulation via $\mathrm{H}_{2} \mathrm{O}_{2}, \mathrm{NOX} 4$ becomes activated, releasing large amounts of superoxides resulting in oxidative stress. Therefore, increased NOX4 expression is recognised to be associated with early progression of atherosclerotic plaque [17]. This study demonstrated that under $\mathrm{H}_{2} \mathrm{O}_{2}$ induced oxidative stress, NOX4 expression is significantly up-regulated compared to the DMSO control. However, after treatment with RB phenolic extracts, at $250 \mu \mathrm{g} / \mathrm{mL}$ concentration, the expression of NOX4 is restored to its original state as observed in DMSO control. Similar findings have been previously reported where they examined the effect of the olive oil phenolic fraction on the angiogenic responses in HUVECs. They also observed that the olive oil extract was able to lower vascular endothelial growth factor-induced angiogenic responses by modulating the expression of several genes, including NOX4 [13].

\subsection{Effect on Anti-Inflammatory Genes under Oxidative Stress Conditions}

The results from this study demonstrated the ability of RB-derived phenolic compounds to down-regulate the pro-inflammatory genes, ICAM1, eNOS, CD39 and CD73 (Figure 3), thereby indicating potential for anti-inflammatory activity respectively and reducing the impact of ROS. ICAM1 is a pro-inflammatory cytokine that facilitates endothelial adhesion of circulating leukocytes and is reported to increase under oxidative stress conditions [18]. The presence and increased expression of ICAM1 in atherosclerotic plaques and lesion-prone hyper-cholesterolemic animals have 
been previously reported [19]. Therefore, lowering the ICAM1 expression may have therapeutic benefits against oxidative stress induced CVD as it can prevent migration of leukocytes and prevent further progression of inflammation leading to the formation of fatty streaks in the endothelium [18]. Under $\mathrm{H}_{2} \mathrm{O}_{2}$ induced oxidative stress conditions, treatment with $\mathrm{RB}$ phenolic extract resulted in significant down-regulation of ICAM1 in HUVECs, thereby reducing the inflammatory status of the cells (Figure 3). A similar effect was observed in the study conducted by Callcott et al. [7], where pre-treatment with Reiziq whole grain rice polyphenol extracts significantly reduced ICAM1 expression (50-250 $\mu \mathrm{g} / \mathrm{mL}$ ) in HUVECs under oxidative stress. Therefore, the results from this study indicate that the cardioprotective compounds reside mainly in the RB layer as the samples tested were also from Australian grown, Reiziq variety.

eNOS enzyme synthesises NO, a potent vasodilator that is identified to play an essential role in protecting against thrombosis and atherogenesis [5]. NO transfers electrons from NADPH through the flavins in the carboxy-terminal reductase domain to the heme in the amino-terminal oxygenase domain [20]. When the flow of electrons through eNOS is disturbed, it results in increased ROS production in the vascular endothelial cells. Therefore, a significant decrease in the expression and activity of eNOS results in acceleration of atherosclerosis [21]. The present study demonstrates that the expression of $e N O S$ gradually increased with RB phenolic extracts, particularly at $250 \mu \mathrm{g} / \mathrm{mL}$ under oxidative stress conditions, suggesting that phenolic compounds in RB ameliorate the oxidative stress in vascular endothelial cells. This is similar to the findings by Madeira et al. [22] where they report that polyphenolic compounds from grape skin extract and red wine respectively induced $e N O S$ activation, providing beneficial effects to the cardiovascular system.

\section{Immunomodulatory Genes}

Extracellular purinergic mediated cell activation via $C D 39$ and $C D 73$ expression of immunomodulatory molecules is recognised to have significant implication in thrombosis, inflammatory response, tissue re-modelling and repair during vascular injury [23]. CD39 hydrolyses phosphate groups by converting ATP to AMP, which is then dephosphorylated into adenosine by CD73 [8]. ATP release is a warning signal released by damaged cells that act as an immunostimulatory signal, whereas adenosine is an immunoregulatory signal which results in an anti-inflammatory, anti-thrombotic and vasodilatory response [24]. Consequently, the balance between ATP and adenosine concentration is crucial in immune homeostasis, and therefore, CD39 and CD73 expression is finely regulated for appropriate immune response regulation [25]. Polyphenols derived from red wine have been shown to inhibit platelet aggregation and increase CD39 activity in rat platelets in vitro [12]. Another study conducted on wild-type mice has demonstrated that ablation of $C D 73$ has minimal effect on in vivo thrombosis, however, increased CD39 expression is recognised to attenuate in vivo arterial thrombosis [26]. In this study, treatment with RB phenolic extracts reduced the expression of $C D 39$ and $C D 73$. These results are in agreement with Melzig [27], who stated that flavonols such as quercetin, myricetin and kaempferol are known to inhibit the activity of the adenosine deaminase in aortic endothelial cells. It is important to note that the treatment with RB-derived phenolic compounds prevented the increase in oxidative stress caused by $\mathrm{H}_{2} \mathrm{O}_{2}$ exposure (Figure 3). These results support the suggestion that treatment with $\mathrm{RB}$ extract was able to avoid the changes caused by $\mathrm{H}_{2} \mathrm{O}_{2}$ exposure, maintaining balanced levels of ATP and adenosine molecules that exhibit potent anti-inflammatory and immunosuppressive actions. Thus, based on our results, we can suggest that the use of RB-derived phenolic compounds is a promising strategy in the treatment of oxidative stress induced by $\mathrm{H}_{2} \mathrm{O}_{2}$.

\section{Materials and Methods}

\subsection{Reagents}

All chemicals and reagents used in this study were purchased from Promega Corporation (Madison, WI, USA), Bio-Rad (Hercules, CA, USA) or Sigma-Aldrich (St. Louis, MO, USA). 


\subsection{Rice Bran Derived Phenolic Extract Preparation}

Commercially stabilised RB (drum-dried), from an Australian grown Reiziq rice variety, was obtained from SunRice milling plant in Leeton, New South Wales and subsequently stored at $4{ }^{\circ} \mathrm{C}$ until further analysis. Phenolic compounds were extracted from stabilised RB using acetone/water/acetic acid (70:29.5:0.5, v/v) mixture as described by Rao et al. [28]. The extract was reconstituted in 10\% dimethyl sulfoxide (DMSO) and stored at $-20{ }^{\circ} \mathrm{C}$ prior to cell culture studies.

\subsection{Cell Culture Conditions}

Experiments were performed with HUVECs purchased from Sigma-Aldrich (St. Louis, MO, USA). HUVECs were maintained in complete endothelial cell growth medium from Cell Applications Inc. (San Diego, CA, USA) at $37{ }^{\circ} \mathrm{C}$ in $5 \% \mathrm{CO}_{2}$ and used before the ninth passage. The cell count for experimental seeding was achieved with Muse ${ }^{\circledR}$ Cell Analyzer from Luminex Corporation (Austin, TX, USA).

\subsection{Cytotoxicity Assay}

Cytotoxicity of RB phenolic extracts was examined using a resazurin red cytotoxicity assay wherein HUVEC cells were seeded into 96-well plates at a density of 5000 cells per well and incubated for $24 \mathrm{~h}$ in the complete endothelial cell culture medium. HUVECs were then treated with $200 \mu \mathrm{L}$ of freshly prepared RB phenolic extract at various concentrations (25, 50, 100, 250, 500, 750 and 1000 $\mu \mathrm{g} / \mathrm{mL}$ ) for 2, 4, 6 and $8 \mathrm{~h}$ time periods. $0.01 \%$ DMSO served as a negative control. Subsequently, $200 \mu \mathrm{L}$ of resazurin red solution $(14 \mathrm{mg} / \mathrm{L})$ was added to each well and incubated for an additional $4 \mathrm{~h}$ at $37^{\circ} \mathrm{C}$ in $5 \% \mathrm{CO}_{2}$. The absorbance was measured on a microplate reader (FLUOstar Omega microplate reader, BMG Labtech, Offenburg, Germany) at 570 and $600 \mathrm{~nm}$ against a resazurin red blank. The percentage of cell viability was calculated using the equation as described by [7].

\subsection{Experimental Design and Induction of Oxidative Stress}

HUVECs were seeded at a density of 300,000 cells per well into 6-well plates and incubated for $24 \mathrm{~h}$. After overnight incubation, cells were treated with RB phenolic extracts (25, 50, 100 and 250 $\mu \mathrm{g} / \mathrm{mL}$ ) for $2 \mathrm{~h}$. The cells were then washed with pre-warmed phosphate buffered saline (PBS) and treated with a $200 \mu \mathrm{M}$ concentration of hydrogen peroxide $\left(\mathrm{H}_{2} \mathrm{O}_{2}\right)$ for $1 \mathrm{~h}$. All experiments were undertaken in triplicates.

\subsection{Ribonucleic Acid (RNA) Extraction}

The total RNA was isolated using the SV Total RNA Isolation System (Promega, Madison, WI, USA) according to the manufacturer's instructions. Briefly, cells were washed with ice cold PBS, scraped with $175 \mu \mathrm{L}$ of RNA lysis buffer containing $\beta$-mercaptoethanol. Subsequently, $350 \mu \mathrm{L}$ of RNA dilution buffer was added and incubated at $70{ }^{\circ} \mathrm{C}$ for $3 \mathrm{~min}$. After centrifugation, the supernatant was mixed with $200 \mu \mathrm{L}$ of $95 \%$ ethanol, placed into a spin basket assembly and DNAse digested. The columns were then washed twice with $600 \mu \mathrm{L}$ RNA solution. RNA was eluted in nuclease-free water and stored at $-80{ }^{\circ} \mathrm{C}$ until further use.

\subsection{Complementary Deoxyribonucleic Acid (cDNA)}

The quality of RNA was determined using a NanoDrop ${ }^{\mathrm{TM}}$ 2000c Spectrophotometer from Thermo Fisher Scientific (Waltham, MA, USA). After which, cDNA synthesis was conducted using GoScript $^{\mathrm{TM}}$ Reverse Transcriptase (Promega, Madison, WI, USA) as per the manufacturer's instructions. Briefly, Oligo $(\mathrm{dT})_{15}$ Primer and a reverse transcription reaction mix containing GoScript ${ }^{\mathrm{TM}} 5 \times$ reaction buffer, $\mathrm{MgCl}_{2}$ (final concentration 1.5-5.0 mM), PCR nucleotide mix (final concentration $0.5 \mathrm{mM}$ each $\mathrm{dNTP}$ ), recombinant RNAsin ${ }^{\circledR}$ ribonuclease inhibitor (optional), GoScript ${ }^{\mathrm{TM}}$ reverse transcriptase and nuclease-free water was added to each sample and cDNA synthesis was performed. The cycling 
conditions comprised of annealing at $25^{\circ} \mathrm{C}$ for $5 \mathrm{~min}$, extension at $42{ }^{\circ} \mathrm{C}$ for $1 \mathrm{~h}$ and inactivation of reverse transcriptase for $15 \mathrm{~min}$ at $70^{\circ} \mathrm{C}$.

\subsection{Primer Sequences}

Primers used for quantitative real-time polymerase chain reaction (qPCR) examinations are listed in Table 1. All of the qPCR primers were designed using Primer3 software and synthesized by Sigma-Aldrich (St. Louis, MO, USA). The amplification efficiency was determined to be in the range of $90-110 \%$ for all the primers prior to commencing qPCR.

Table 1. The nucleotide sequences of the PCR primers used to assay gene expression by qPCR.

\begin{tabular}{ccc}
\hline Gene & Forward Primer & Reverse Primer \\
\hline Nrf2 & ATGACAATGAGGTTTCTTCGG & CAATGAAGACTGGGCTCTC \\
NQO1 & ACATCACAGGTAAACTGAAGG & TCAGATGGCCTTCTTTATAAGC \\
HO1 & AACTCCCTGGAGATGACTC & CTCAAAGAGCTGGATGTTGAG \\
eNOS & GTTACCAGCTAGCCAAAGTC & TCTGCTCATTCTCCAGGTG \\
NOX4 & TATCCAGTCCTTCCGTTGG & CCAATTATCTTCTGTATCCCATCTG \\
ICAM-1 & GATAGCCAACCAATGTGCT & TTCTGGAGTCCAGTACACG \\
CD39 & TCAAATGTAGTGTGAAAGGCTC & TACACTCCTCAAAGGCTCTG \\
CD73 & CATTCCTGAAGATCCAAGCA & AGGAGCCATCCAGATAGAC \\
$\beta$ - actin & GAAGATCAAGATCATTGCTCCTC & ATCCACATCTGCTGGAAGG \\
\hline
\end{tabular}

\subsection{Quantitative Real-Time Polymerase Chain Reaction ( $q P C R$ )}

Gene expression was conducted in the CFX96 Touch ${ }^{\mathrm{TM}}$ Real-Time PCR Detection System (Bio-Rad) using SsoAdvanced ${ }^{\mathrm{TM}}$ Universal SYBR ${ }^{\circledR}$ Green Supermix (Bio-Rad) detection according to the manufacturer's instructions. Briefly, SsoAdvanced ${ }^{\mathrm{TM}}$ Universal SYBR ${ }^{\circledR}$ Green Supermix $(9 \mu \mathrm{L})$ containing forward and reverse primer was added to 96-well PCR plate along with $1 \mu \mathrm{L}$ of cDNA in each well. $\beta$-actin served as the reference gene. The cycling conditions comprised of $95^{\circ} \mathrm{C}$ for $3 \mathrm{~min}$, $95{ }^{\circ} \mathrm{C}$ for $10 \mathrm{~s}$ and $58^{\circ} \mathrm{C}$ for $30 \mathrm{~s}$ repeated for 40 cycles. Melt curve was generated at $65^{\circ} \mathrm{C}$ for $5 \mathrm{~s}$ and $95^{\circ} \mathrm{C}$ for $50 \mathrm{~s}$. The endpoint or cycle threshold $\left(C_{t}\right)$ values were obtained for all genes tested. The mean normalized expression of genes were determined using Q-gene software application as described by Muller et al. [29]. $\beta$-actin served as the housekeeping gene

\subsection{Statistical Analysis}

Statistical analysis was performed using one-way analysis of variance (ANOVA), followed by post-hoc Tukey's multiple comparisons test using GraphPad Prism 7 software (GraphPad Software Inc., San Diego, CA, USA) at a level of $p<0.05$. The results are reported as mean \pm standard error of mean (SEM).

\section{Conclusions}

In summary, RB-derived phenolic compounds displayed a cytoprotective effect on vascular endothelial cells under oxidative stress. Pre-treatment with RB phenolic extracts resulted in the regulation of antioxidant (Nrf2, NQO1, HO1 and NOX4) and anti-inflammatory (ICAM1, eNOS, CD39 and $C D 73)$ genes. Since RB contains several bioactive chemicals including $p$-coumaric acid, caffeic acid, vanillic acid, ferulic acid and syringic acid, the effects observed in this study may be due to the synergistic effect of these bioactive compounds. With relatively few human clinical studies on the antioxidant activities of cereals being currently available, information regarding the bioavailability of polyphenolic extracts is limited. Therefore, in vivo metabolomic studies are essential to examine the antioxidant and anti-inflammatory potential of cereal grains to essentially utilise functional cereal grain by-products such as RB. 
Author Contributions: N.S. performed the experiments outlined in this study and drafted the manuscript. N.F., C.L.B., L.J.S., A.B.S. were involved in the experimental study design, preparation and review of this manuscript.

Funding: This study was funded by the Australian Research Council Industrial Transformations Training Centre for Functional Grains (Project ID 100737) and from AgriFutures, Australia (PRJ-011503). We acknowledge the financial support provided by the Graham Centre for Agricultural Innovation, Australia to cover the publication costs.

Acknowledgments: The authors would like to acknowledge SunRice, Australia for providing the rice bran samples used within this study. The authors would also like to acknowledge the Graham Centre for Agricultural Innovation, Australia for providing the publication support grant. This project is funded by the Australian Research Council Industrial Transformation Training Centre for Functional Grains Centre. N.S. is a recipient of a PhD scholarship from the Australian Research Council Industrial Transformation Training Centre for Functional Grains (Project ID 100737) and also the recipient of a top-up scholarship from AgriFutures, Australia (PRJ-011503).

Conflicts of Interest: The authors declare no conflicts of interest.

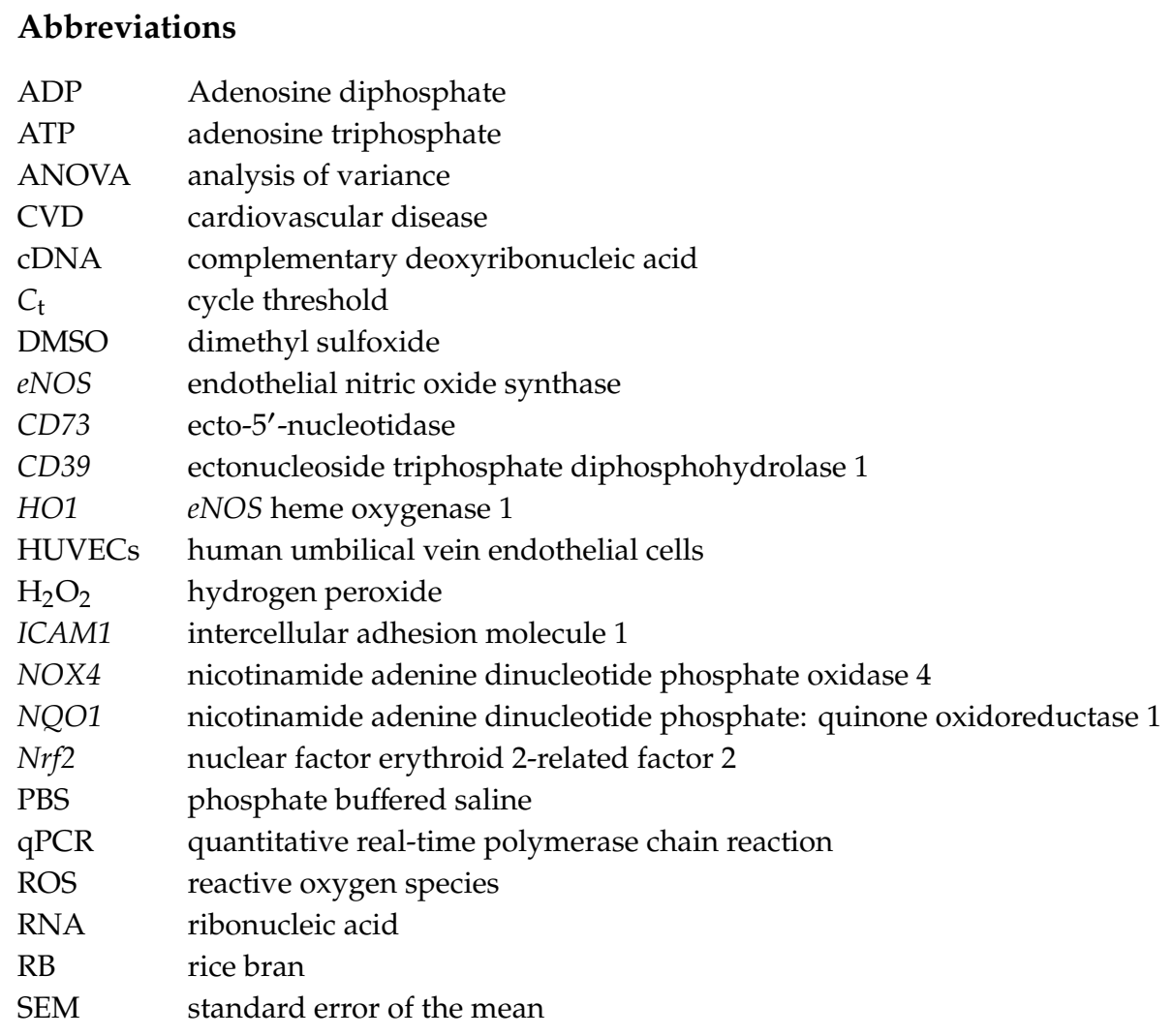

\section{References}

1. Fuentes, E.; Palomo, I. Mechanisms of endothelial cell protection by hydroxycinnamic acids. Vasc. Pharmacol. 2014, 63, 155-161. [CrossRef]

2. Reuland, D.J.; McCord, J.M.; Hamilton, K.L. The role of $n r f 2$ in the attenuation of cardiovascular disease. Exerc. Sport Sci. Rev. 2013, 41, 162-168. [CrossRef] [PubMed]

3. Luo, S.; Lei, K.; Xiang, D.; Ye, K. Nqo1 is regulated by pten in glioblastoma, mediating cell proliferation and oxidative stress. Oxid. Med. Cell. Longev. 2018, 2018. [CrossRef] [PubMed]

4. Loboda, A.; Damulewicz, M.; Pyza, E.; Jozkowicz, A.; Dulak, J. Role of nrf2/ho-1 system in development, oxidative stress response and diseases: An evolutionarily conserved mechanism. Cell. Mol. Life Sci. 2016, 73, 3221-3247. [CrossRef] [PubMed]

5. He, W.; Kwesiga, M.P.; Gebreyesus, E.; Liu, S. Nitric oxide and oxidative stress-mediated cardiovascular functionality: From molecular mechanism to cardiovascular disease. In Vascular Biology; IntechOpen: London, UK, 2019.

6. Zelko, I.N.; Folz, R.J. Regulation of oxidative stress in pulmonary artery endothelium. Modulation of extracellular superoxide dismutase and nox4 expression using histone deacetylase class I inhibitors. Am. J. Respirat. Cell Mol. Biol. 2015, 53, 513-524. [CrossRef] [PubMed] 
7. Callcott, E.T.; Blanchard, C.L.; Oli, P.; Santhakumar, A.B. Pigmented rice-derived phenolic compounds reduce biomarkers of oxidative stress and inflammation in human umbilical vein endothelial cells. Mol. Nutr. Food Res. 2018, 62, 1800840. [CrossRef] [PubMed]

8. Antonioli, L.; Pacher, P.; Vizi, E.S.; Haskó, G. Cd39 and cd73 in immunity and inflammation. Trends Mol. Med. 2013, 19, 355-367. [CrossRef] [PubMed]

9. Ungvari, Z.; Bagi, Z.; Feher, A.; Recchia, F.A.; Sonntag, W.E.; Pearson, K.; De Cabo, R.; Csiszar, A. Resveratrol confers endothelial protection via activation of the antioxidant transcription factor $n r f 2$. Am. J. Physiol. Heart Circul. Physiol. 2010, 299, H18-H24. [CrossRef] [PubMed]

10. Park, J.S.; Jung, J.S.; Jeong, Y.H.; Hyun, J.W.; Le, T.K.V.; Kim, D.H.; Choi, E.C.; Kim, H.S. Antioxidant mechanism of isoflavone metabolites in hydrogen peroxide-stimulated rat primary astrocytes: Critical role of hemeoxygenase-1 and expression. J. Neurochem. 2011, 119, 909-919. [CrossRef]

11. Butsat, S.; Siriamornpun, S. Antioxidant capacities and phenolic compounds of the husk, bran and endosperm of thai rice. Food Chem. 2010, 119, 606-613. [CrossRef]

12. Caiazzo, E.; Tedesco, I.; Spagnuolo, C.; Russo, G.L.; Ialenti, A.; Cicala, C. Red wine inhibits aggregation and increases atp-diphosphohydrolase (cd39) activity of rat platelets in vitro. Nat. Product Commun. 2016, 11, 1934578X1601100618. [CrossRef]

13. Calabriso, N.; Massaro, M.; Scoditti, E.; D’Amore, S.; Gnoni, A.; Pellegrino, M.; Storelli, C.; De Caterina, R.; Palasciano, G.; Carluccio, M.A. Extra virgin olive oil rich in polyphenols modulates vegf-induced angiogenic responses by preventing nadph oxidase activity and expression. J. Nutr. Biochem. 2016, 28, 19-29. [CrossRef] [PubMed]

14. Manach, C.; Williamson, G.; Morand, C.; Scalbert, A.; Rémésy, C. Bioavailability and bioefficacy of polyphenols in humans. I. Review of 97 bioavailability studies. Am. J. Clin. Nutr. 2005, 81, 230S-242S. [CrossRef] [PubMed]

15. Satta, S.; Mahmoud, A.M.; Wilkinson, F.L.; Yvonne Alexander, M.; White, S.J. The role of nrf2 in cardiovascular function and disease. Oxid. Med. Cell. Longev. 2017, 2017. [CrossRef] [PubMed]

16. Patel, R.; Maru, G. Polymeric black tea polyphenols induce phase ii enzymes via nrf2 in mouse liver and lungs. Free Rad. Biol. Med. 2008, 44, 1897-1911. [CrossRef] [PubMed]

17. Ugusman, A.; Zakaria, Z.; Hui, C.K.; Nordin, N.A.M.M. Piper sarmentosum inhibits icam-1 and nox4 gene expression in oxidative stress-induced human umbilical vein endothelial cells. BMC Complement. Altern. Med. 2011, 11, 31. [CrossRef]

18. Shalini, V.; Pushpan, C.K.; Sindhu, G.; Jayalekshmy, A.; Helen, A. Tricin, flavonoid from njavara reduces inflammatory responses in hpbmcs by modulating the p38mapk and pi3k/akt pathways and prevents inflammation associated endothelial dysfunction in huvecs. Immunobiology 2016, 221, 137-144. [CrossRef]

19. Iiyama, K.; Hajra, L.; Iiyama, M.; Li, H.; DiChiara, M.; Medoff, B.D.; Cybulsky, M.I. Patterns of vascular cell adhesion molecule-1 and intercellular adhesion molecule-1 expression in rabbit and mouse atherosclerotic lesions and at sites predisposed to lesion formation. Circul. Res. 1999, 85, 199-207. [CrossRef]

20. Förstermann, U.; Li, H. Therapeutic effect of enhancing endothelial nitric oxide synthase (enos) expression and preventing enos uncoupling. Br. J. Pharmacol. 2011, 164, 213-223. [CrossRef]

21. Leikert, J.r.F.; Räthel, T.R.; Wohlfart, P.; Cheynier, V.; Vollmar, A.M.; Dirsch, V.M. Red wine polyphenols enhance endothelial nitric oxide synthase expression and subsequent nitric oxide release from endothelial cells. Circulation 2002, 106, 1614-1617. [CrossRef]

22. Madeira, S.V.F.; Auger, C.; Anselm, E.; Chataigneau, M.; Chataigneau, T.; De Moura, R.S.; Schini-Kerth, V.B. Enos activation induced by a polyphenol-rich grape skin extract in porcine coronary arteries. J. Vasc. Res. 2009, 46, 406-416. [CrossRef] [PubMed]

23. Kanthi, Y.M.; Sutton, N.R.; Pinsky, D.J. Cd39: Interface between vascular thrombosis and inflammation. Curr. Atheroscl. Rep. 2014, 16, 425. [CrossRef] [PubMed]

24. Bono, M.R.; Fernández, D.; Flores-Santibáñez, F.; Rosemblatt, M.; Sauma, D. Cd73 and cd39 ectonucleotidases in t cell differentiation: Beyond immunosuppression. FEBS Lett. 2015, 589, 3454-3460. [CrossRef] [PubMed]

25. Jian, R.; Sun, Y.; Wang, Y.; Yu, J.; Zhong, L.; Zhou, P. Cd73 protects kidney from ischemia-reperfusion injury through reduction of free radicals. Apmis 2012, 120, 130-138. [CrossRef] [PubMed]

26. Covarrubias, R.; Chepurko, E.; Reynolds, A.; Huttinger, Z.M.; Huttinger, R.; Stanfill, K.; Wheeler, D.G.; Novitskaya, T.; Robson, S.C.; Dwyer, K.M. Role of the $c d 39 / c d 73$ purinergic pathway in modulating arterial thrombosis in mice. Arterioscl. Thromb. Vasc. Biol. 2016, 36, 1809-1820. [CrossRef] 
27. Melzig, M. Inhibition of adenosine deaminase activity of aortic endothelial cells by selected flavonoids. Planta Medica 1996, 62, 20-21. [CrossRef] [PubMed]

28. Rao, S.; Callcott, E.T.; Santhakumar, A.B.; Chinkwo, K.A.; Vanniasinkam, T.; Luo, J.; Blanchard, C.L. Profiling polyphenol composition and antioxidant activity in australian-grown rice using uhplc online-abts system. J. Cereal Sci. 2018, 80, 174-179. [CrossRef]

29. Muller, P.; Janovjak, H.; Miserez, A.; Dobbie, Z. Processing of gene expression data generated by quantitative real-time rt pcr (vol 32, pg 1378, 2002). Biotechniques 2002, 33, 514.

(C) 2019 by the authors. Licensee MDPI, Basel, Switzerland. This article is an open access article distributed under the terms and conditions of the Creative Commons Attribution (CC BY) license (http://creativecommons.org/licenses/by/4.0/). 